\title{
CTSA E O ENSINO DE FÍSICA: UM ESTUDO DE CASO
}

\author{
Donizete Aparecido Buscatti Junior
}

Universidade Estadual Paulista - UNESP, Programa de Pós-Graduação em Educação para a Ciência, Bauru, SP. E-mail: djrbuscatti@hotmail.com

\section{RESUMO}

Tendo como pressuposto a necessidade de se repensar a formação de professores para uma sociedade tecnológica - o que foi alvo de fartos debates educacionais pelo movimento CTSA -, desenvolvemos um estudo de caso em um curso de licenciatura em Física de uma instituição federal de ensino. Os objetivos foram identificar as concepções acerca das relações sociedadetecnologia-ambiente e analisar como tais concepções se aplicariam em uma aula. Como instrumento de coleta de dados foram utilizados questionários e a análise de uma apresentação feita pelos alunos, que foi gravada e transcrita. Os resultados apontaram que, em geral, a visão dos futuros docentes atende às orientações dos documentos oficiais: praticamente todos defendem a ideia de formar cidadãos conscientes dos efeitos que a tecnologia e a ciência tem na nossa sociedade. A análise da prática, no entanto, evidenciou que foram discutidos apenas os pontos benéficos da ciência, expondo uma visão distorcida do real desenvolvimento científico e do papel deste na sociedade.

Palavras-chave: CTSA, Ensino de Física, Formação de Professores, Educação Ambiental, Estudo de caso

\section{CTSA AND PHYSICAL EDUCATION: A CASE STUDY}

\begin{abstract}
Taking for granted the need to rethink the training of teachers for a technological society - which was the subject of educational debates fed by CTSA movement - we developed a case study on a degree course in Physics of a federal educational institution. The objectives were to identify the conceptions of society-technology-environment relations and analyze how these concepts would apply in a class. As data collection instrument questionnaires were used and the analysis of a presentation made by the students, which was recorded and transcribed. The results showed that, in general, the vision of the future teachers meets the guidelines of the official documents: almost all support the idea of forming citizens aware of the effects that technology and science has in our society. The practical analysis, however, revealed that were discussed only beneficial points of science, exposing the distorted picture of the true scientific development and the role of the society.
\end{abstract}

Keywords: CTSA, Physical Education, Teacher Training, Environmental Education, Case Study 


\section{INTRODUÇÃO}

É praticamente um consenso o fato de, com a franca expansão da tecnologia e suas reminiscências - em especial, o rápido acesso à informação - será necessário repensar a questão sobre que tipo de formação a escola deverá fornecer aos seus alunos. Podemos especular: uma formação da qual o sujeito saia com total domínio (e, consequentemente, dependente) das ferramentas tecnológicas? Algo no sentido de formar um aluno cético aos avanços tecnológicos e científicos, dado que temos provas concretas de que estes foram responsáveis por danos irreversíveis em nosso planeta? Entre a idolatria e o desprezo, temos convicção de que a ponderação leva ao melhor caminho.

Os documentos oficiais colocam que, de forma geral, a escola deve ter condições de formar um cidadão crítico e consciente de seu meio (BRASIL, 2002). Portanto, levando-se em a realidade atual, o ideal seria que nossos alunos concluíssem a educação básica com uma visão plural dos aspectos norteiam os avanços da ciência e tecnologia, ou seja, que leve em conta que tratam-se de avanços consequentes, que podem ao mesmo tempo aumentar a expectativa de vida humana e causar danos significativos ao ambiente comprometendo o próprio futuro da vida sobre a terra. Tal assunto (formação ideal do aluno para os tempos atuais) é objeto fartas discussões no terreno dos especialistas em Educação, no entanto, outra questão decorre desse problema: que formação um professor deve ter para poder trabalhar nesse sentido em sala de aula.

O presente artigo inspira-se justamente no problema da formação de professores para uma sociedade tecnológica, ou mais especificamente, na formação de professores de física para uma realidade na qual os avanços tecnocientíficos influenciam diretamente a vida das pessoas. Realizamos uma pesquisa que visou explicitar as concepções de futuros professores de Física sobre o tema da relação entre o desenvolvimento científico e as questões ambientais; que, na literatura, se classifica como pertencente ao movimento Ciência, Tecnologia, Sociedade e Ambiente (CTSA), movimento que forneceu o referencial teórico aqui adotado.

\section{FUNDAMENTAÇÃO TEÓRICA - O MOVIMENTO CTSA E O ENSINO DE CIÊNCIAS}

A industrialização crescente e inconsequente (assim como outros fatores) colocou a questão dos impactos ambientais no rol dos principais assuntos de discussão em praticamente todos os meios acadêmicos. Disso, passou-se a refletir sobre a natureza do conhecimento e seu papel na sociedade, assim como buscou-se desenvolver uma visão crítica sobre as relações entre ciência, tecnologia e sociedade (AULER; BAZZO, 2001; BAZZO, 1998; CRUZ; ZYLBERSZTAJN, 2001). A partir da década de 70, esse movimento desenvolveu concepções de currículos no ensino de ciências que colocavam as questões CTSA como incorporadas aos conteúdos escolares (ANGOTTI; AUTH, 2001).

Muitas propostas de cursos CTSA tem sido feitas tanto para a educação básica quanto para a graduação e pós-graduação. Em linhas gerais, para a educação básica, visa-se a promoção de uma educação científica e tecnológica aos cidadãos, de modo a auxiliar o sujeito a construir conhecimentos, habilidades e valores necessários para tomar decisões concernentes às questões de ciência e tecnologia e possivelmente solucionar tais questões (SANTOS; MORTIMER, 2000).

Alguns autores utilizam a perspectiva do movimento CTSA com uma visão crítica, na qual desenvolve-se uma concepção de educação ambiental conhecida como EA crítica, também denominada emancipatória ou transformadora. Para Loureiro (2004):

A Educação Ambiental transformadora é aquela que possui um conteúdo emancipatório, em que a dialética entre forma e conteúdo se realiza de tal maneira que as alterações da atividade humana, vinculadas ao fazer educativo, impliquem mudanças individuais e coletivas, estruturais e conjeturais, econômicas e culturais. 
Nota-se que o autor endossa a articulação entre a educação ambiental e os conteúdos tradicionalmente tratados no contexto escolar. Ainda sobre o tratamento de tais questões como componentes curriculares, Ricardo (2007) enfatiza que essa nova proposta:

Não se trata de simplificar currículos, reduzindo conteúdos, mas sim de ressignificá-los socialmente, de forma que possam ser agentes de transformação social em um processo de educação problematizadora que resgate o papel da formação da cidadania. Buscar a vinculação, portanto, dos conteúdos científicos com temas CTSA de relevância social e abrir espaço em sala de aula para debates de questões sociocientíficas são ações fundamentais no sentido do desenvolvimento de uma educação crítica questionadora do modelo de desenvolvimento científico e tecnológico.

Por fim, no que diz respeito à formação de professores, julgamos relevante colocar que, para Brito (2008) muitas concepções e crenças construídas pelos futuros professores ao longo da suas trajetórias escolares acompanham-nos durante alguma parte de sua formação inicial. Ainda segundo os autores:

A formação que receberam os futuros professores enquanto alunos do ensino básico e superior e o modelo tradicional de ensino a que foram submetidos influenciam e dificultam a realização de propostas curriculares que se aproximem de uma perspectiva CTSA do ensino de ciências e biologia.

\section{PROCEDIMENTOS METODOLÓGICOS}

Tendo como fundamento os pressupostos teóricos do movimento CTSA descritos na seção anterior, fizemos uma pesquisa qualitativa com o objetivo principal de identificar como (ou se) os futuros docentes de física trabalhariam questões ambientais em suas aulas e quais são as suas impressões sobre o tema. Para tanto, julgamos pertinente adotar um estudo de caso, tendo como referencial metodológico Sturman (1998), para o qual este tipo de metodologia visa entender um caso para entender e descobrir como as coisas ocorrem e por que ocorrem.

A pesquisa desenvolveu-se em um curso de licenciatura em física de uma instituição federal de ensino, situada em uma cidade do interior de São Paulo; e foi composta em duas partes.

Inicialmente, aplicou-se um questionário aos alunos do quarto e último ano (vinte sujeitos) do curso com questões abertas visando evidenciar concepções sobre os temas de interesse da pesquisa. Na discussão dos resultados, colocamos os enunciados das questões para que a análise se dê de forma mais clara, diferenciamos as falas de diferentes alunos por letras aleatórias.

A segunda parte da pesquisa foi realizada na disciplina de Prática de ensino de Física IV (componente curricular do último ano do curso, e ministrada pelo autor desse trabalho), onde solicitou-se para que cada aluno fizesse uma apresentação para a turma - com duração de uma hora aula (50 minutos) - destinada ao ensino médio e que explorasse a relação entre a física e as questões ambientais da atualidade. Os temas foram de livre escolha dos alunos, assim como o material disponível para a apresentação (lousa, giz e datashow). As apresentações foram gravadas, transcritas e analisadas segundo indicações de André (1998).

\section{RESULTADOS E DISCUSSÃO}

Iniciaremos a análise dos questionários abertos, dado que foram aplicados antes das apresentações. 


\section{QUESTIONÁRIOS}

Segue o enunciado da primeira questão:

1) Na sua opinião, temáticas que versem sobre a relação ciência/ambiente e tecnologia/ambiente devem ser componentes do currículo escolar dos cursos de licenciatura em Física.

Inicialmente, frisamos que está pergunta obteve resposta afirmativa para todos os questionários analisados. Todavia, vamos nos ater às justificativas dadas.

Aluno A: Sim, pois devemos ter em nossas mentes o 'para que ensinar física', buscando ligar as temáticas com o cotidiano vivido hoje, as tecnologias, a história; ensinar, por exemplo, como funciona uma geladeira, por que ocorre as estações do ano.

Notamos uma interessante e necessária preocupação com a vinculação entre a física escolar e a realidade, não em um sentido estritamente pragmatista, mas no intuito de mostrar que a ciência está presente no cotidiano do aluno, algo identificado como um componente cultural (ZANETIC, 1989). De um modo geral, o "como funciona", se não for trabalhado de forma utilitarista, enrique muito a aula e atende ao propósito de formação que discutimos na introdução.

Aluno B: Sem dúvida que sim (...). Pela lei e pelos PCN, o objetivo da escola é criar cidadãos e o pleno desenvolvimento da pessoa, e não criar físicos e cientistas.

$\mathrm{O}$ aluno se refere às orientações complementares aos Parâmetros Curriculares, os PCN+ (BRASIL, 2002), que expressam bem a ampliação dos objetivos educacionais para além do acúmulo de informações disciplinares estritas na forma de três grandes competências: representação e comunicação, investigação e compreensão, contextualização sócio-cultural. Todavia, é importante colocar que a afirmação destacada não foi cautelosa, uma fez é possível ser cidadão e físico. Superar a imagem de que a ciência é desenvolvida por pessoas frias, isentas de capacidade reflexiva é um dos objetivos centrais do ensino de ciências escolar (NARDI, 2009).

\section{APRESENTAÇÕES}

De uma forma geral, as apresentações se desenvolveram com a seguinte estrutura:

- Tema: todos concernentes à física moderna. Uma apresentação versou sobre o efeito fotoelétrico, uma sobre partículas elementares e todas as outras foram sobre o assunto de Física nuclear e radiações.

- Desenvolvimento: em todas as apresentações, o conceito foi definido formalmente antes da sua contextualização. A questão de que esse seria o método mais adequado ou não para se trabalhar um conceito científico em sala de aula não está presente no escopo desse artigo, por tratar-se da linha de pesquisa relacionada com ensino/aprendizagem. Todavia, concordamos com Menezes (2009) que diz que a discussão e percepção de um conceito científico pode se desenvolver de forma independente da sua estrutura formal. Pode-se entender e refletir sobre os efeitos das radiações nucleares sem necessariamente se recorrer ao atual modelo atômico. Se houvesse essa "proibição para menores" nos conceitos da ciência contemporânea, não faria sentido existir divulgação científica.

- Fechamento: absolutamente todas as apresentações terminaram com a ênfase nos benefícios tecnológicos oriundos da física moderna. Por exemplo, falou-se sobre células fotovoltaicas para o assunto do efeito fotoelétrico, como uma das principais fornecedoras de energia limpa da atualidade; mas não se discutiu como ficaria o descarte de tais células, as consequências que o uso excessivo pode ter e a possibilidade de todas as camadas sociais terem acesso a essa tecnologia. No geral, não identificamos possibilidades de um debate pluralista conforme indicamos nos pressupostos teóricos.

\section{CONCLUSÃO}


Foi possível constatar que a percepção dos futuros docentes acerca das temáticas envolvendo a relação CTSA é, em linhas gerais positiva, e as justificativas para tal, apesar tomarem caminhos diversos, confluem para a ideia da necessidade de inserir o aluno nas discussões concernentes às novas tecnologias. Um cidadão bem formado é um aquele que entenda os mecanismos de funcionamento do seu meio, que tenha noções de cultura geral e uma visão de mundo provinda de uma alfabetização científica mínima.

Todavia, em conjunto com os conhecimentos científicos que serão tratados em sala de aula, é necessário criar condições para um debate com ideias divergentes acerca do uso e das concepções de ciência. A argumentação, e com ela o senso crítico, são tão essenciais quanto o conteúdo em si da disciplina. O ensinar ciência deve acontecer simultaneamente com o ensinar sobre ciência. Tais eram nossos pressupostos educacionais que não foram identificados nas apresentações propostas.

O motivo de haver uma incompatibilidade entre a percepção - formar cidadãos preparados para o século XXI - e a ação - evidenciar apenas os aspectos positivos do desenvolvimento científico - sinaliza os caminhos que a formação de professores de ciência deve tomar.

\section{REFERÊNCIAS}

Andre, M.E.D. Etnografia da prática escolar. $2^{2}$ Ed. São Paulo: Papirus editora, 1998.

ANGOTTI, J. A. P.; AUTH, M. A. Ciência e tecnologia: implicações sociais e o papel da educação. Ciência \& Educação, v. 7, n. 1, p.15-27, 2001. https://doi.org/10.1590/S1516$\underline{73132001000100002}$

AULER, D.; BAZZO, W. A. Reflexões para a implementação do movimento CTS no contexto educacional brasileiro. Ciência \& Educação, v. 7, n. 1, p.1-13, 2001. https://doi.org/10.1590/S1516$\underline{73132001000100001}$

BRASIL, Secretaria de Educação Média e Tecnológica. PCN+ Ensino Médio: orientações educacionais complementares aos Parâmetros Curriculares Nacionais. Ciências da Natureza, Matemática e suas Tecnologias. Brasília: MEC, SEMTEC, 2002.

BAZZO, W. A. Ciência, tecnologia e sociedade: e o contexto da educação tecnológica. Florianópolis: Ed. da UFSC, 1998.

Brito, L.D., Souza, M.L. \& Freitas, D. Formação Inicial de Professores de Ciências e Biologia: a visão da natureza do conhecimento científico e a relação CTSA. Rev. Interacções, 2008.

CRUZ, S. M. S. C.; ZYLBERSZTAJN, A. O enfoque ciência, tecnologia e sociedade e a aprendizagem centrada em eventos. In: PIETROCOLA, M. (org.). Ensino de Física: conteúdo e epistemologia numa concepção integradora. Florianópolis: Ed. da UFSC, 2001. p. 171-196.

LOUREIRO, C. F. B. Trajetória e fundamentos da educação ambiental. São Paulo: Cortez, 2004.

MENEZES, L. C.. Ensino de Física: Reforma ou Revolução?. In: André Ferrer P. Martins. (Org.). Física ainda é Cultura?. 1ed.São Paulo: Livraria da Física, v. 1, p. 25-45, 2009.

NARDI, R.. Ensino de Ciências e Matemática I: Temas sobre Formação de Professores. 1. ed. São Paulo: http://books.scielo.org/id/g5q2h, 2009. v. 01. 480p . 
RICARDO, Elio Carlos. Educação CTSA: obstáculos e possibilidades para sua implementação no contexto escolar. Ciência \& Ensino (Online), v. 01, p. 01-12, 2007.

SANTOS, W. L. P. dos; MORTIMER, E. F. Uma Análise de Pressupostos Teóricos da Abordagem C-T-S (Ciência-Tecnologia-Sociedade) no Contexto da Educação Brasileira. Ensaio - pesquisa em educação em ciências, v. 2, n. 2, p.133-162, 2000.

Sturman, A. Case study methods. In: Husén, T. \& Postlethwaite, T.N. Internacional Encyclopedia of Education. Oxford, Pergamon Press (1998).

Zanetic, J. Física também é cultura. Tese de doutorado apresentada ao Instituto de Física e à Faculdade de Educação da USP, Universidade de São Paulo, São Paulo, 1989. 